\title{
Failure Analysis of Small Gap Brazing of a Stainless Steel Heat Exchanger
}

\author{
Michael Neff, Michael Neff Associates, Culver City, California
}

\begin{abstract}
A heat exchanger used to cool hot hydrogen in a high purity gas train failed in service. The heat exchanger failed in a brazed joint near the inlet (hot side) portion between the body and the tube sheet. The brazing joint was cross sectioned to open the fracture and determine the brazing joint geometry. It was found that the thickness of the brazing joint around the circumference of the joint varied from 0.001 minimum to 0.004 " maximum. The use of a nickel-boron brazing alloy in this assembly corrected the problem.

Keywords: Brazing, Nicrobraz, Heat Exchanger
\end{abstract}

\section{SUMMARY}

A 316L Stainless Steel heat exchanger fabricated by furnace brazing failed at the braze joint in a high purity gas delivery application. Nicrobraz 51, a high chromium nickel alloy with phosphorus modification, was originally chosen for this heat exchanger because of the high corrosion resistance provided by the high chromium. The heat exchanger had been used successfully in previous applications with lower thermal stresses, but in the subject application in which it was used to cool hydrogen the thermal stresses were more severe. Hydrogen at $375^{\circ} \mathrm{C}$ entered the heat exchanger through openings in the tubesheet (Figures 1 and 2). Water at $20^{\circ} \mathrm{C}$ entered the tube bundle cavity through an inlet just adjacent to the failed tubesheet. The high differential temperature between the hydrogen and the water coolant caused high radial stresses leading to fracture of the brazing alloy.

The recommended joint clearance for the Nicrobraz 51 alloy is very critical. While the flow characteristics of the alloy are good, the brazing joint failed in a brittle manner due to the high stresses introduced by the thermal differential. The brittle fracture was observed emanating from a groove in the center portion of the brazing joint, Figure 5.

The crack failed the entire cross section of the brazed joint in the upper quadrants of the circle, between 9 o'clock to 3 o'clock, (Figure 3). Toward the bottom quadrants, the crack terminated, so that the total separation of the gap was 0.004 " at 12 o'clock and only 0.001 " at 6 o'clock. Metallographic examination of the fracture showed that the brazing alloy was thicker near the groove, and this was the area where the brittle fracture appeared to originate, Figure 7.

In order to further evaluate the strength of the brazing alloy, a series of tensile tests were conducted in order to correlate the gap thickness with the strength of the brazed joint. It was found that the there was a sharp decrease in strength as the gap thickness increased for this alloy. The sensitivity of the brazing alloy strength to gap thickness was not as critical for standard boron modified brazing alloys. As a result of the testing, the brazing alloy was changed to a $\mathrm{BNi}-3(3.1 \% \mathrm{~B})$ which is much more forgiving with respect to embrittlement in thicker gaps, and the problem did not recur. 


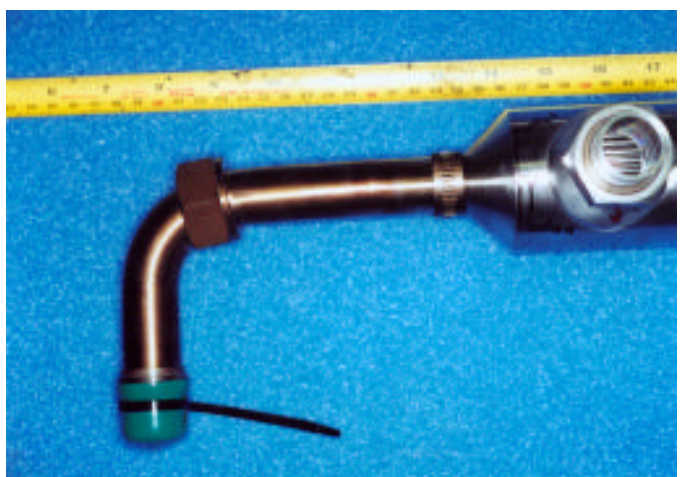

Figure 1. An optical photograph of the inlet side of the tube heat exchanger.

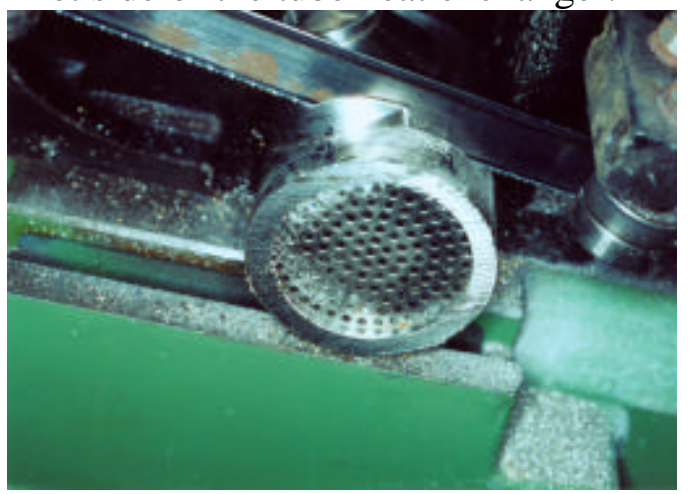

Figure 2. An optical photograph of the hydrogen inlet tubesheet braze assembly.

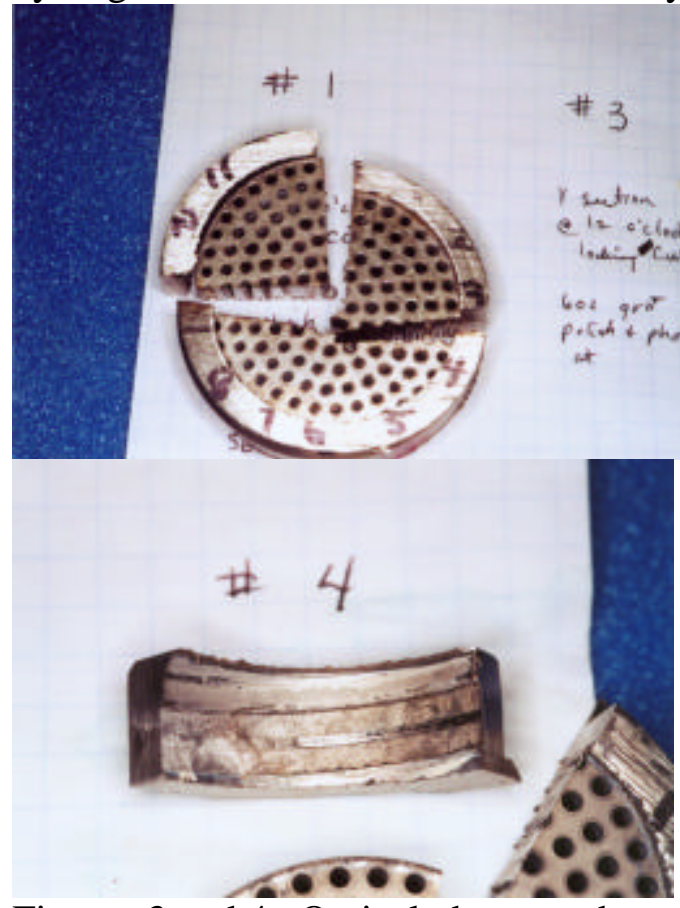

Figures 3 and 4 . Optical photographs showing how the sections were removed for SEM examination and cross section. Also showing the brazing joint fracture.

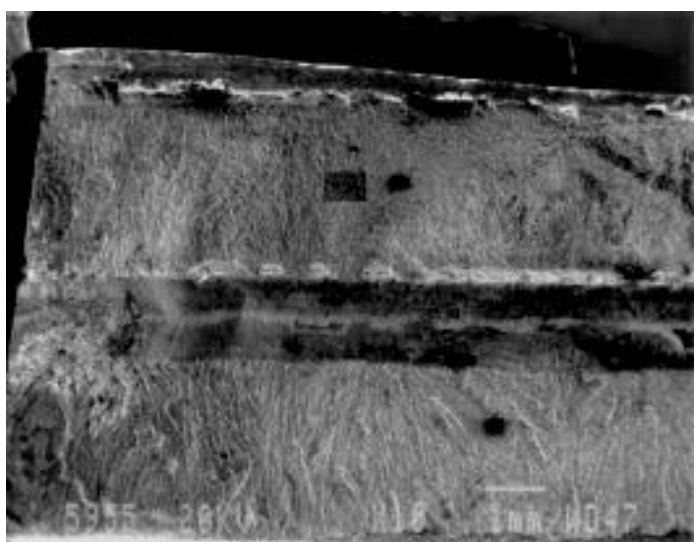

Figure 5. An SEM photograph showing the fracture initiating along a void in the center of the brazing joint.

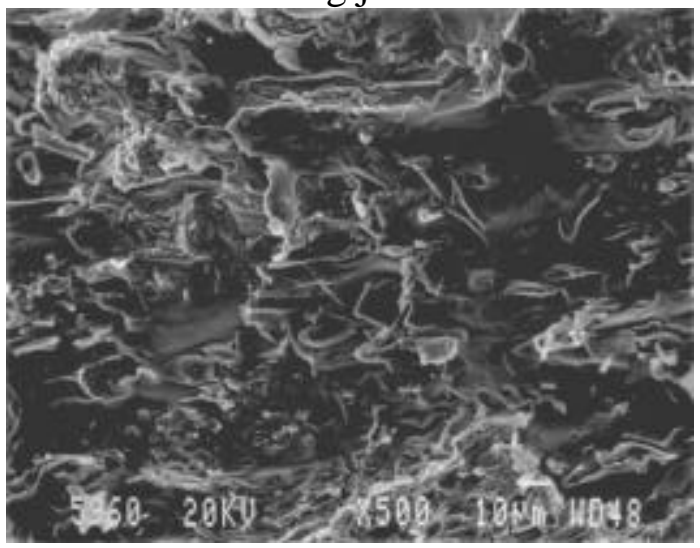

Figure 6. An SEM photograph showing the brittle fracture surface morphology.

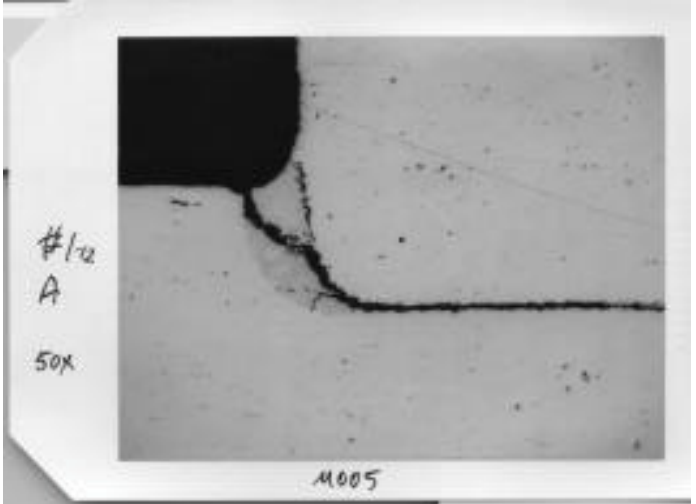

Figure 7. A metallographic section through the failed brazing joint showing the crack initiating in a thick portion of the braze joint next to the void. 